\title{
1986 - A BRILLIANT YEAR FOR THE GREAT WHITE BIRD
}

ERNIE KUYT and J. PAUL GOOSSEN, Canadian Wildlife Service, 4999 -98 Avenu€ Edmonton, Alberta. T6B 2X3

The 1986 fall migration of Whooping Cranes was the slowest in 12 years. Over the past 26 years, an average of $82 \%$ of the crane population summering in the Wood Buffalo National Park (WBNP) area had reached the Aransas National Wildlife Refuge (ANWR) winter range by 10 November, but in 1986 only $25 \%$ had reached the refuge by that date, according to T.V. Stehn, United States Fish and Wildlife Service (USFWS). The reasons for the protracted fall migration are unclear but probably relate to a relative absence of severe fall weather along the flyway and excellent habitat conditions on the summer range. These factors may have kept the cranes in and near WBNP for longer than usual periods. B. Johns, Canadian Wildlife Service (CWS), advised that fall sightings of Whooping Cranes in Saskatchewan were few in 1986 and it appears that most of the cranes ignored the prairie stubble fields where in most years the birds will feed on waste barley and wheat for several weeks. Perhaps the cranes already were in excellent condition and did not require the lengthy staging period in Saskatchewan.

Information obtained from Aransas indicates that 111, Whooping Cranes including 21 juveniles were accounted for by 2 February 1987, easily surpassing the 1985 all-time record of 97 birds which included 16 young. The total of 111 contains three birds not on the Aransas refuge. One of these, a bird hatched in 1985, left the refuge and is now wintering with Sandhill Cranes about $70 \mathrm{~km}$ to the northeast. Two other birds, also colour-banded, were observed in December 1986 and January 1987 in Oklahoma but had not yet reached ANWR.
One of the latter two birds, an 8-montr old chick, was feared lost in mic November when its parents (one of whicl is colour banded) arrived on the Texa refuge without it. On 30 January th chick's existence was confirmed when i was observed feeding with a flock of Sanc hill Cranes in Oklahoma (T.V. Stehn, pers comm.).

CWS located 27 Whooping Crane nest in 1986 in and near WBNP. One of th nests was that of a new nesting pair, con sisting of a 3-year-old and a 4-year-olı bird. Evidence of a 28 th nest was obtain ed on 4 August when we saw a pair $c$ adult cranes (one of which was a colou banded 3-year-old) with a single chick is an area where we had not previousl found a nest. In addition, we had nc known about one of the three Whoopin: Crane families which arrived at ANWI with an unbanded chick. If that family alsı originated from the WBNP area (as is like ly), CWS biologists will have the challeng ing task of finding two unknown nest site in 1987. It is clear however, that in 1981 a minimum of 29 pairs of Whoopin Cranes nested.

Even though we found three new pair in 1986, the breeding population increas ed by only one pair from 1985. Two pairs one of which nested only in 1984 anı 1985, failed to nest in 1986. Last May w found a 9-year-old male dead near its nes and it remains to be seen if the female wil find another mate.

It is likely that the breeding populatio in 1987 will be similar to that of th previous year and may contain from 29-3 pairs. If habitat conditions in 1987 are a 


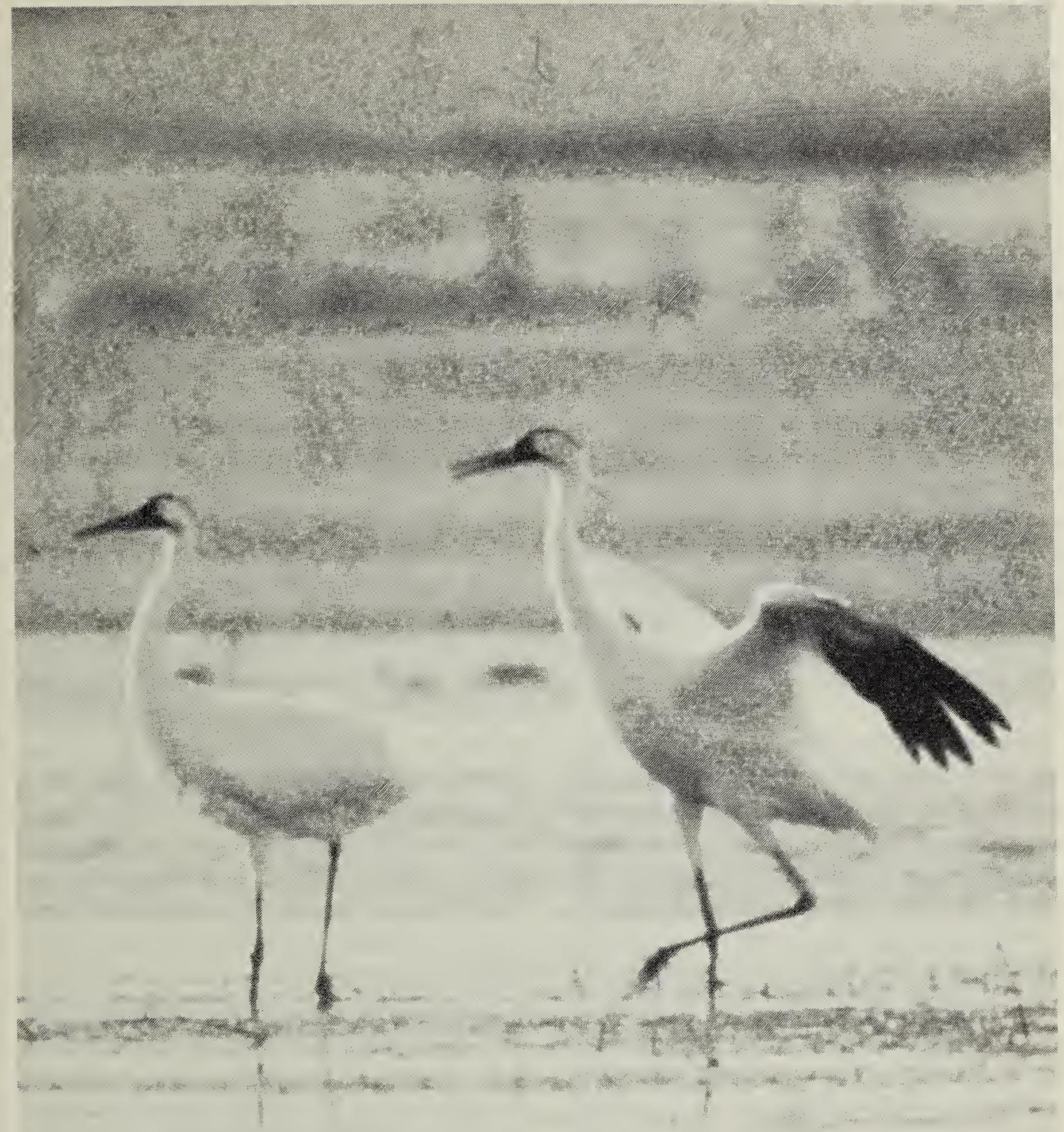

Whooping Cranes

Lorne Scott

45(2). June 1987 
good as those between 1984 and 1986 and if any of the 3-year-old cranes from the large 1984 class breed in 1987, there could be as many as 33 nesting pairs.

The years 1987-1990 will be exciting for crane watchers as the breeding population should grow by the recruitment of new breeders from the excellent production years of 1984, 1985 and 1986 when 15, 16 and 21 chicks, respectively, were raised in WBNP. T.V. Stehn (pers. comm.) advised that all of the 16 birds hatched in 1985 have survived to date and are present at ANWR.

After the annual removal of surplus eggs (for the Grays Lake population, see below) in May 1986, one egg remained in each of 26 nests then known to exist. Both eggs had been removed from the nest where the adult had died.

As a result of egg viability tests at nests, we knew that most, if not all of the remaining eggs were live. Six non-viable eggs were removed and in a few cases, live eggs were substituted in nests which had doubtful or non-viable eggs. Ensuring that a live egg remained in each nest in WBNP (by means of viability tests and egg substitutions) contributed greatly to the excellent hatching success in 1986 with 23 of the 26 eggs hatching. Nineteen of the 23 chicks were still alive on 10 August when a team of CWS and USFWS biologists and volunteers, supported by Parks Canada, banded 17 of the 19 chicks as well as the chick from a family discovered on 4 August. Two chicks, known to be in the Klewi River area could not be located and they remained unbanded as well as the chick from the family first seen at ANWR.

Of the 25 surplus eggs removed, 15 live eggs were placed in nests of Greater Sandhill Cranes in the Grays Lake National Wildlife Refuge in Idaho while four live eggs and six non-viable eggs were sent to the Patuxent Wildlife Research Center near Laurel, Maryland.

Although 11 of the 15 eggs hatched at Grays Lake, an extremely serious drought took a heavy toll of the Whooping Crane chicks and only two eventually feldged. Many Sandhill Crane chicks also succumbed in the area. Predators (Coyote and Red Fox) destroyed two of the Whooping Crane eggs and likely took several of the drought-weakened chicks. Two of the four live eggs shipped to the Patuxent Wildlife Research Center hatched and the juveniles are doing well. The six non-viable eggs from WBNP and four eggs which failed at Grays Lake and Patuxent were analysed by staff at Patuxent. Two Grays Lake eggs and one from Patuxent contained embryos which had died 2-5 days from hatching. Of the remaining seven nonviable eggs, two contained 10-15 day old embryos (these eggs therefore died well before the egg pick-up), four eggs did not contain a detectable embryo but were deemed to have been fertile and only one egg was infertile.

The total captive population is now about 40 birds and about 25 wild birds are believed to exist in the experimental population which annually migrates between New Mexico and Idaho and adjoining states. With the Wood Buffalo-Aransas population at 111 birds there are about 176 Whooping Cranes in the world, a vast improvement over the 21 birds in existence in 1941.

We acknowledge information provided by R.C. Drewien on the experimental population, data from T.V. Stehn on population counts at ANWR, and information provided by J.W. Carpenter on the test results of unhatched eggs carried out at the Patuxent Wildlife Research Center. Environment Canada - Parks in Fort Smith, N.W.T., provided important logistic and manpower support. We thank all these contributors. 